\title{
Publisher Correction: Harnessing big 'omics' data and Al for drug discovery in hepatocellular carcinoma
}

Bin Chen (1), Lana Garmire, Diego F. Calvisi, Mei-Sze Chua, Robin K. Kelley and Xin Chen (1)

Nature Reviews Gastroenterology \& Hepatology (2020) https://doi.org/10. 1038/s41575-019-0240-9 Published online 03 January 2020

In this Review, the accept date was inadvertently omitted. It should be 06 November 2019. This error has been corrected online.

https://doi.org/10.1038/s41575-020-0288-6 I Published online: 11 March 2020

(C) Springer Nature Limited 2020 